\title{
Plantas transgênicas resistentes a insetos e organismos não-alvo: predadores, parasitóides e polinizadores
}

\author{
Marina Regina Frizzas* \\ Charles Martins de Oliveira**
}

\begin{abstract}
RESUMO - Plantas geneticamente modificadas resistentes aos insetos oferecem benefícios à agricultura moderna. No entanto, esta tecnologia pode afetar o controle biológico natural e a biodiversidade por meio de efeitos diretos e indiretos das plantas transgênicas sobre o valor adaptativo e comportamental de predadores, parasitóides, polinizadores e outros artrópodes não-alvo. Neste artigo, são discutidos os impactos ou os efeitos potenciais de plantas transgênicas resistentes a insetos sobre organismos nãoalvo, com ênfase em artrópodes predadores, parasitóides e polinizadores, e os principais estudos com plantas transgênicas resistentes a insetos, publicados nos últimos dez anos.
\end{abstract}

Palavras-chave: OGM. Insecta. Inimigos naturais.

\section{Insect-resistant transgenic plants and non-target organisms: predators, parasitoids and pollinators}

\begin{abstract}
Insect-resistant transgenic plants offers numerous benefits to agriculture. Although this technology has the potential to disrupt natural biological control and to affect biodiversity through both direct and indirect side effects of the plants on the fitness or behaviour of predators, parasitoids, pollinators and others arthropods non-target. In this article, we discuss the potential impacts of the transgenic plants resistant to insects on non-target organisms, with emphasis in the effects on predators, parasitoids and pollinators arthropods. This review focuses the main studies with transgenic plants resistant to insects published during the last ten years.
\end{abstract}

Keywords: OGM, Insecta, natural enemies.

\footnotetext{
* Professora do curso de Biologia da FACS/UniCEUB. Centro Universitário de Brasília (UniCEUB), Faculdade de Ciências da Saúde (FACS), SEPN 707/907, 70790-075, Brasília, DF - Brasil. Email: frizzas@yahoo.com.br

** Pesquisador da Embrapa Cerrados. Embrapa Cerrados - BR 020 Km 18 (Brasília/Fortaleza) - 73310970, CP 08223, Planaltina, DF - Brasil. Email: charles@ cpac.embrapa.br
} 


\section{Introdução}

Plantas transgênicas ou plantas geneticamente modificadas que expressam genes com atividade inseticida representam nova alternativa para o controle de insetos, além de serem consistentes com a filosofia do manejo integrado de pragas (MIP). Atualmente, culturas como soja, milho, algodão, batata e fumo, têm sido modificadas geneticamente, para expressar as proteínas derivadas de Bacillus thuringiensis Berliner, e são utilizadas em escala comercial em vários países, atingindo a área de cerca de 102 milhões de hectares (JAMES, 2006). As principais vantagens do uso das plantas geneticamente modificadas são: aumento na produção (BETZ et al., 2000); menores níveis de micotoxinas (DOWD, 2000) e redução na aplicação de inseticidas (WANG et al., 2004; ROMEIS et al., 2006), principalmente os, de largo espectro, favorecendo a manutenção de inimigos naturais (GOULD, 1998), que auxiliam no controle de pragas e contribuem para retardar a evolução da resistência (MASCARENHAS; LUTTRELL, 1997).

No entanto, algumas dúvidas em relação à entomofauna têm despertado o interesse dos pesquisadores e dos órgãos de regulamentação. Os principais questionamentos são: a possibilidade de as plantas transgênicas afetarem os organismos não-alvo de diferentes níveis tróficos (principalmente parasitóides, predadores, polinizadores e lepidópteros não-alvo) e a possibilidade de evolução de resistência de pragas às proteínas de $B$. thuringiensis, expressas pelas plantas continuamente durante todo o ciclo da cultura.

O presente trabalho tem como objetivo discutir o efeito das plantas geneticamente modificadas sobre organismos não-alvo, com enfoque em predadores, parasitóides e polinizadores.

\section{Plantas geneticamente modificadas}

O século XX foi caracterizado por grandes descobertas que tiveram profundo impacto no melhoramento genético de plantas. Há muitos anos, as plantas cultivadas tem sido manipuladas geneticamente pelo homem, por meio do melhoramento clássico. Atualmente, o melhoramento de plantas pode recorrer às técnicas da engenharia 
genética. Entre as estratégias de plantas geneticamente modificadas resistentes a insetos, encontram-se: B. thuringiensis (Bt), a mais utilizada; além de colesterol oxidase; lectinas; inibidores de $\alpha$-amilase; inibidores de proteinases; proteínas inseticidas vegetativas; quitinases; peroxidase; entre outras (CAROZZI; KOZIEL, 1997).

A grande maioria das plantas geneticamente modificadas resistentes a insetos expressa genes derivados da bactéria $B$. thuringiensis. Insetos e $B t$ têm coexistido por milhões de anos, já que $B$. thuringiensis é uma bactéria que habita naturalmente o solo, é gram-positiva, esporulante e anaeróbica facultativa. Além disso, é empregada há muitos anos como um inseticida microbiano por agricultores e, mais recentemente, é utilizada como nova ferramenta para o controle de pragas, por meio da sua expressão nas plantas transgênicas. A atividade entomopatogênica desse microrganismo deve-se à presença de uma inclusão cristalina produzida durante a esporulação (pró-toxinas). $\mathrm{O}$ cristal, composto por proteínas denominadas $\delta$-endotoxinas ou proteínas cristal (Cry), tem ação extremamente tóxica e específica para larvas de insetos de algumas ordens, como Lepidóptera, Diptera e Coleóptera, dependendo da proteína (MONNERAT; BRAVO, 2000).

As pró-toxinas, quando ingeridas, são solubilizadas pelo $\mathrm{pH}$ alcalino do trato intestinal do inseto-alvo e clivadas pelas proteases intestinais, tornando-se peptídeos de menor tamanho, colhidos por receptores específicos encontrados no epitélio, os quais iniciam um processo de destruição tecidual, que colabora para a paralisia muscular. Isso leva o inseto à morte, que também pode ocorrer em função de uma segunda causa associada à primeira, a multiplicação bacteriana na hemolinfa, determinando um processo septicêmico (GILL, 1995).

A área mundial com plantas geneticamente modificadas é de 102 milhões de hectares, sendo que, no período entre 1996 e 2006, a área plantada aumentou mais de 60 vezes. Os quatro principais países em termos de área cultivada são Estados Unidos (54\% da área total), Argentina (18\%), Brasil (11\%) e Canadá (6\%), sendo as principais culturas a soja, o milho e o algodão (JAMES, 2006).

Apesar dos benefícios, existem possíveis riscos relativos às plantas geneticamente modificadas. Entre os principais, estão: seleção de populações de insetos resistentes às proteínas $B t$; ocorrência de fluxo gênico com parentes silvestres relacionados com possível alteração na agressividade do genótipo; impacto das 
proteínas $B t$ sobre as espécies não-alvo (inimigos naturais, pragas secundárias, insetos de solo, polinizadores); efeitos adversos na biodiversidade, no ecossistema e nas comunidades bióticas (WANG et al., 2004; FERRY et al., 2006).

\section{Impacto potencial das plantas geneticamente modificadas sobre os inimigos naturais}

Para que uma planta transgênica seja considerada efetivamente uma tecnologia e possa integrar-se aos sistemas produtivos, há necessidade de que ela não represente riscos à saúde e ao ambiente, condição essencial para que a comercialização seja realizada sem restrições (FONTES; MELO, 1999). Portanto, existe grande preocupação com relação ao resultado das interações entre os organismos geneticamente modificados e o meio ambiente, uma vez que o impacto das plantas transgênicas não pode ser sempre previsto.

Ultimamente tem-se discutido como as plantas geneticamente modificadas contendo $B$. thuringiensis interagem com os organismos não-alvo dos diferentes níveis tróficos, pois, no campo, as culturas abrigam não somente os insetos praga, mas também outros artrópodes (parasitóides e predadores), os quais desempenham importante papel na regulação das populações de herbívoros. Em termos ecológicos, essa hierarquia é chamada de interação tritrófica, em que a planta representa o primeiro nível trófico, o inseto praga, herbívoro ou presa, o segundo nível e os inimigos naturais, o terceiro nível. Sendo assim, como muitos inseticidas convencionais, esta nova tecnologia tem o potencial de alterar o controle biológico natural por meio de efeitos diretos e indiretos das plantas geneticamente modificadas no custo adaptativo comportamental ou ecológico dos inimigos naturais (SCHULER et al., 1999).

Os mecanismos por meio dos quais as plantas resistentes afetam os inimigos naturais são complexos. Os possíveis efeitos das plantas geneticamente modificadas na dinâmica populacional dos inimigos naturais dependem de ampla gama de fatores, como, por exemplo, o nível de resistência da planta, a especificidade da proteína expressa, em quais tecidos será expressa e por quanto tempo, a presença de plantas suscetíveis próximas e o manejo da cultura, ou seja, aplicação de inseticidas, controle de plantas daninhas, entre outros (SCHULER, 2000). Além dos efeitos diretos da planta sobre a biologia e ou comportamento do inimigo natural em decorrência de substâncias 
químicas ou outras fontes de alimento, como pólen, flores e seiva, há os feitos indiretos, ou seja, efeito da planta sobre a praga que afeta o inimigo natural (HOY et al., 1998).

Como as proteínas de $B$. thuringiensis são expressas em altas doses nos tecidos verdes das plantas geneticamente modificadas e, dependendo do promotor utilizado, também podem ser expressas no pólen, nas sementes, nas raízes e em outras partes da planta, isso poderia também afetar os inimigos naturais de diferentes maneiras. Sugadores podem adquirir a proteína expressa na seiva das plantas transgênicas quando se alimentam, e isso poderia também afetar os inimigos naturais. No entanto, Raps et al. (2001) não detectaram a proteína Cry1Ab no floema de milho geneticamente modificado nem no "honeydew" de Rhopalosiphum padi (L.), entretanto a proteína foi detectada em larvas e fezes de Spodoptera littoralis (Boisduval).

Estudos de laboratório e casa-de-vegetação têm revelado efeito em inimigos naturais quando a praga suscetível ao $B t$ é usada como presa ou hospedeiro, sem nenhuma indicação de efeito tóxico. Em campo, observou-se que a abundância e a atividade de predadores e parasitóides são similares em áreas com e sem transgênicos, entretanto, em áreas com aplicação de inseticidas, observaram-se efeitos negativos sobre esses organismos (ROMEIS et al., 2006).

\section{Efeitos sobre predadores}

Como os predadores são importantes agentes de controle natural, especial atenção tem sido dada aos possíveis efeitos das plantas geneticamente modificadas sobre estes insetos. Entretanto, de 87 estudos realizados para avaliar a resposta da proteína $B t$ a predadores, 70 mostraram pouco ou nenhum efeito (GLARE; O’CALLAGHAN, 2000). Nas espécies de predadores, tanto o adulto como as larvas são de vida livre. Em função da sua mobilidade e da gama de hospedeiros, os predadores são geralmente menos afetados pela redução na abundância de uma espécie de presa em particular (SCHULER et al., 1999).

O grande questionamento é como as plantas geneticamente modificadas interagem com os organismos não-alvo dos diferentes níveis tróficos. Possíveis efeitos ocorreriam: 
a) quando os predadores se alimentassem do pólen de plantas geneticamente modificadas; no entanto não foram verificados efeitos do pólen contendo a proteína Cry1Ab em Coleomegilla maculata (DeGeer), Orius insidiosus Say e Chrysoperla carnea Stephens e do pólen contendo a proteína Cry3A em C. maculata (PILCHER et al., 1997; RIDDICK; BARBOSA, 1998);

b) quando os predadores consumissem presas que se alimentaram da seiva das plantas geneticamente modificadas; em estudos realizados, esta interação não foi observada sobre os predadores avaliados, por exemplo, efeito de pulgões sobre C. carnea (LOZZIA et al., 1998), Chrysoperla externa (Hagen) (DEMARCHI, 2002) e Hippodamia convergens Guérin-Ménéville (DOGAN et al., 1996) e efeito de tripes Anaphothrips obscurus (Müller) sobre Orius majusculus (Reuter) (ZWAHLEN et al., 2000);

c) quando os predadores se alimentassem diretamente da presa que a planta geneticamente modificada visa controlar; isso pode estar relacionado tanto ao efeito direto da proteína sobre o predador como à redução na qualidade nutricional da presa.

Estudos visando avaliar o efeito de Ostrinia nubilalis Hübner sobre o predador O. insidiosus (AL-DEEB et al., 2001) e de Leptinotarsa decemlineata (Say) sobre $C$. maculata (RIDDICK; BARBOSA, 1998) demonstraram não haver efeito da presa sobre o predador. Entretanto, Hilbeck et al. (1998a) verificaram que o predador C. carnea apresentou alta mortalidade quando se alimentou da presa-alvo, O. nubilalis, e de uma presa não-alvo, S. littoralis. Alta mortalidade também foi observada quando os estágios imaturos desse predador se alimentaram diretamente de uma dieta líquida contendo a proteína Cry1Ab (HILBECK et al., 1998b). Contudo, Sims (1995) verificou que a proteína Cry1 Ab, na concentração de $20 \mu \mathrm{g} / \mathrm{ml}$, não afetou os predadores $C$. carnea e $H$. convergens.

A joaninha Harmonia axyridis (Pallas), alimentada com pólen de milho transgênico, não apresentou alterações nas taxas de desenvolvimento, peso e atividade metabólica (ZHANG et al., 2005). Nenhum efeito foi observado para o coleóptero predador Pterostichus madidus (F.), alimentado com larvas que se desenvolveram em canola transgênica (FERRY et al., 2006). 
As plantas transgênicas podem afetar os predadores especialistas e os generalistas de modo diferenciado, ou seja, em baixas densidades populacionais da presa. Os predadores especialistas tendem a dispersar-se mais rapidamente em busca de alimento. Os generalistas podem permanecer na cultura e alimentarem-se de presas alternativas. Riddick et al. (1998) verificaram que Lebia grandis Hentz, predador especialista, foi menos abundante que C. maculata, predador generalista, em campos com $100 \%$ de batata transgênica e em campos com mistura de sementes. Esse aspecto é de grande relevância no contexto do controle biológico, uma vez que os predadores generalistas poderiam permanecer na cultura e contribuir para o controle de pragas. Além disso, Arpaia et al. (1997) verificaram que a atividade predatória de C. maculata poderia diminuir a razão com que $L$. decemlineata se adapta às plantas transgênicas em campos com mistura de sementes, favorecendo o manejo da resistência.

Compostos secundários de plantas, os aleloquímicos, podem afetar os predadores. Essas interações dependem da espécie e do estágio de desenvolvimento do predador exposto e dos compostos envolvidos. Muitos aspectos fisiológicos, ecológicos e comportamentais são governados pelas interações com organismos de outros níveis tróficos. O seqüestro de aleloquímicos, por exemplo, pode prejudicar seus inimigos naturais, uma vez que os herbívoros removem estas substâncias e armazenam-nas em certas partes do corpo para utilização como meio de defesa contra inimigos naturais. Portanto, estas interações também devem ser consideradas para as plantas geneticamente modificadas.

PILCHER et al. (2005) observaram, em plantios consecutivos entre 1996 e 1998, que o milho transgênico (eventos 176 e Bt11) não alterou significativamente a abundância dos predadores generalistas C. maculata, Cycloneda munda (Say), O. insidiosus e C. carnea. Outros estudos também não detectaram efeitos negativos do milho transgênicos sobre predadores (POZA et al., 2005). No entanto, o uso de inseticidas apresentou maior efeito negativo em organismos não-alvo, causando redução de 48\% em 13 táxons de insetos predadores, do que o uso de algodão transgênico, onde as reduções foram de 19\% em 5 taxóns (NARANJO, 2005). Efeito semelhante foi observado em milho (BHATTI et al., 2005; DIVELY, 2005). 


\section{Efeitos sobre parasitóides}

O modo mais óbvio pelo qual as plantas geneticamente modificadas podem afetar os inimigos naturais é a diminuição severa no suprimento de presas. No entanto, este efeito tende a ser mais profundo para os inimigos naturais que se alimentam exclusivamente da praga que a planta transgênica tem especificidade em controlar (SCHULER et al., 1999). Os parasitóides larvais podem ser afetados de diversas maneiras: pela redução na qualidade do hospedeiro, o que reduziria a sobrevivência larval e a fecundidade do parasitóide; ao consumir tecidos do hospedeiro; por não conseguir completar seu desenvolvimento em decorrência da morte prematura do hospedeiro. Os parasitóides adultos podem ser afetados: ao alimentarem-se de flores, seiva, pólen e néctar das plantas geneticamente modificadas contendo proteína $\mathrm{Bt}$; por mudanças na emissão de compostos voláteis pela planta, o que pode interferir na localização hospedeira pelo parasitóide; por mudanças na composição e na emissão de compostos das fezes hospedeiras ou no "honeydew" excretado; por mudanças no comportamento do hospedeiro induzido pelas plantas transgênicas como aumento na movimentação, o que pode afetar o parasitismo (SCHULER et al., 1999).

Por exemplo, a mortalidade do hospedeiro Helicoverpa zea (Boddie) aumentou com o aumento na densidade do seu inimigo natural (MASCARENHAS; LUTTRELL, 1997). Um efeito sinérgico também ocorreu entre o parasitóide Campoletis sonorensis (Cameron) e as plantas de tabaco resistentes a Heliothis virescens (F.), tanto pelo aumento na exposição da praga ao inimigo natural como pelo aumento na taxa de parasitismo (JOHNSON; GOULD, 1992). Johnson et al. (1997) também verificou sinergismo entre $C$. sonorensis e plantas de tabaco transgênicas, mas esse efeito não foi verificado para Cardiochiles nigriceps Viereck. No entanto, Johnson et al. (1997) encontraram dados contraditórios, ou seja, o parasitismo por C. sonorensis diminuiu em plantas transgênicas, e o parasitismo das lagartas suscetíveis foi menor, aumentando o custo adaptativo das lagartas resistentes, o que pode acelerar a adaptação da praga às plantas transgênicas. No entanto, o sinergismo entre a planta resistente e os inimigos naturais também pode acelerar a adaptação da praga às plantas transgênicas (GOULD et al., 1991). 
O aumento do parasitismo pode estar relacionado com a maior movimentação das larvas nas plantas transgênicas, facilitando o encontro pelo parasitóide. Assim, a maior movimentação poderia acarretar em menor alimentação, o que implicaria menor emissão de compostos secundários e afetaria a localização do hospedeiro pelo parasitóide.

A utilização de pragas resistentes a proteínas $B t$, visando avaliar os efeitos da proteína na biologia do parasitóide, pode auxiliar a análise dos riscos ecotoxicológicos. Estudos mostraram que o parasitóide Cotesia plutellae Kurdjumov se desenvolve normalmente em lagartas de $P$. xylostella resistentes e que o parasitóide consegue localizar seu hospedeiro mesmo quando o dano nas folhas é feito artificialmente ou quando é causado por lagartas resistentes (SCHULER et al., 2000). Isso pode contribuir para os programas de manejo integrado de pragas e para o manejo da resistência, já que C. plutellae e B. thuringiensis utilizados conjuntamente são efetivos para o controle de P. xylostella, e os parasitóides poderiam ajudar a controlar a praga no refúgio (áreas com plantas suscetíveis à praga), reduzindo a necessidade de aplicação de inseticidas, o que poderia diminuir a evolução da resistência ao inseticida (CHILCUTT; TABASHNIK, 1999).

As plantas geneticamente modificadas apresentam elevado nível de controle das pragas-alvo. A redução severa no suprimento de presas pode afetar o parasitismo no campo, no entanto Orr e Landis (1997) não verificaram diferenças no parasitismo de massas de ovos de O. nubilalis pelos parasitóides Eriborus terebrans (Gravenhorst) e Macrocentrus grandii Goidanich em áreas de milho transgênico. A porcentagem de parasitismo por Diadegma insulare Cresson, parasitóide de larvas e pupas de $P$. xylostella não diferiu em campos com mistura de plantas transgênicas e convencionais (RIGGIN-BUCCI; GOULD, 1997).

Demarchi (2002), ao estudar a interação tritrófica entre cana transgênica expressando a proteína Cry1Ab, D. saccharalis e o parasitóide Trichospilus diatraeae Cherian \& Margabandhu, também não observou diferenças na porcentagem de parasitismo, na longevidade e na fertilidade do parasitóide e na atratividade da planta transgênica ao parasitóide. Bell et al. (2001), analisando o efeito do inibidor de tripsina (CpTI) presente na dieta de Lacanobia oleracea (L.) sobre o ectoparasitóide Eulophus pennicornis (Nees), verificaram redução no parasitismo, entretanto a fecundidade e a 
longevidade da geração $F_{1}$ do parasitóide não foram afetadas. López e Ferro (1995) e Blumberg et al. (1997) verificaram efeitos adversos nos parasitóides Myiopharus doryphorae (Riley) (taquinídeo) e Microplitis croceipes (Cresson) (braconídeo) em decorrência da redução no vigor e na morte prematura dos hospedeiros, L. decemlineata e Helicoverpa armigera (Hübner), respectivamente.

O milho transgênico (eventos 176 e Bt11) reduziu em 29-60\% a abundância do parasitóide especialista Macrocentrus cingulum Brischke (PILCHER et al., 2005). O parasitóide Apanteles chilonis (Munakata) teve algumas características de seu desenvolvimento negativamente afetadas quando o parasitismo ocorreu em hospedeiro [Chilo suppressalis (Walker)] que se alimentou em arroz transgênico (JIANG et al., 2005). Para o parasitóide C. plutellae, não foram observados efeitos negativos nos parâmetros biológicos de desenvolvimento quando o hospedeiro Plutella xylostella (L.), resistente ao $B t$, alimentou-se em folhas de repolho transgênico, entretanto, para a raça de P. xylostella suscetível, a morte prematura do hospedeiro impediu o desenvolvimento do parasitóide (SCHULER et al., 2004).

\section{Efeitos sobre polinizadores}

A avaliação do efeito dos agentes de controle biológico sobre os polinizadores, principalmente as abelhas, é exigida pelos órgãos de regulamentação. As plantas geneticamente modificadas expressam proteínas com alta especificidade, contudo, em função do promotor utilizado, estas proteínas podem ser expressas no pólen e no néctar das plantas. Portanto, um dos questionamentos é sobre os possíveis efeitos do néctar e do pólen contendo proteínas $B t$ sobre larvas e adultos dos polinizadores. Estudos com larvas e adultos de Apis mellifera L. demonstraram não existir efeitos da proteína sobre o polinizador (SIMS, 1995; ARPAIA, 1996). Todavia, alguns efeitos adversos foram verificados, por exemplo, por Vandenberg (1990), que encontrou alta mortalidade de $A$. mellifera com a proteína de B. thuringiensis var. tenebrionis. Picard-Nizou et al. (1997) verificaram que a proteína CpTI diminuiu a ação das abelhas, e Malone et al. (1995) observaram que os inibidores de tripsina foram tóxicos aos adultos. Para o algodão transgênico, não foram observados efeitos negativos em polinizadores (HOFS et al., 2005). 


\section{Efeitos sobre outros organismos não-alvo}

Espécies de lepidópteros não-alvo podem ser suscetíveis às proteínas de $B t$, uma vez que elas podem entrar em contato com o pólen das plantas transgênicas por meio das plantas daninhas ou outras plantas existentes nas bordaduras ou próximas à cultura. Pulverizações de $B t$ foram tóxicas as espécies de lepidópteros não-alvo Papilio glaucus L., Papilio canadenses Rothschild \& Jordan e Callosamia promethea (Drury), e esses efeitos persistiram por cerca de 30 dias, após a pulverização (JOHNSON et al., 1995). No entanto, o pólen de milho Bt não afetou a espécie Papilio polyxenes Fabr. em condições de laboratório e de campo (WRAIGHT et al., 2000).

Especial atenção tem sido dada à borboleta monarca, Danaus plexippus (L.), depois que estudos mostraram alta mortalidade desta espécie quando as lagartas se alimentaram de folhas de Asclepias spp. contendo pólen de milho Bt (LOSEY et al., 1999). A densidade de borboletas monarca por planta é maior em habitat agrícola, com sobreposição espacial e temporal entre a emissão de pólen e o estágio de lagarta (OBERHAUSER et al., 2001). Entretanto, alguns fatores podem reduzir esta exposição, ou seja, a ocorrência de chuva pode remover $54-86 \%$ do pólen das folhas. Folhas da porção superior, principal local de alimentação dos primeiros ínstares da monarca, têm 30-50\% da densidade de pólen das folhas da porção intermediária, e os primeiros ínstares não se alimentam das nervuras das folhas, cuja densidade de pólen é 1,5-1,9 vezes maior (PLEASANTS et al., 2001). Outro fator que deve ser considerado é a suscetibilidade dos diferentes estádios de desenvolvimento da monarca, sendo que os últimos ínstares são 12 a 23 vezes menos suscetíveis à proteína $B t$ que os primeiros (HELLMICH et al., 2001).

O risco ecológico é uma função da exposição (dose) e da resposta toxicológica (efeito), portanto a quantidade da proteína existente no pólen é de grande importância. Alguns estudos têm mostrado que existe grande variação na quantidade de pólen existente nos diferentes eventos de milho, ou seja, o evento $176(90,5 \pm 2,6 \mathrm{ng} / \mathrm{g})$

apresenta cerca de 40 vezes mais proteína que o evento $810(2,1 \pm 0,3 \mathrm{ng} / \mathrm{g})$ (WRAIGHT et al., 2000). Portanto, pólen contendo as proteínas Cry1Ab (eventos Bt11 
e Mon810), Cry1F e Cry9C não tiveram efeitos sobre lagartas da borboleta monarca ao contrário do evento 176 contendo a proteína Cry1Ab (HELLMICH et al., 2001; STANLEY-HORN et al., 2001).

Por outro lado, quando se comparam campos não-transgênicos tratados com o inseticida piretróide lambda-cialotrina, a sobrevivência da borboleta monarca foi drasticamente reduzida, e muitas lagartas morreram poucas horas após a alimentação (STANLEY-HORN et al., 2001). Além dos aspectos considerados, outros fatores são de grande importância, por exemplo, a destruição de seu habitat no México e as freqüentes aplicações de inseticidas. Nesse contexto, acredita-se que o efeito das plantas geneticamente modificadas sobre a borboleta monarca pode ser muito menor quando comparado com o uso indiscriminado de inseticidas (PIMENTEL; RAVEN, 2000).

\section{Plantas geneticamente modificadas e as interações tritróficas}

Como resposta ao dano causado pelos insetos, as plantas sintetizam e emitem compostos voláteis como importante fonte para a localização do hospedeiro pelos parasitóides. Plantas de tabaco, algodão e milho produzem compostos voláteis em resposta ao dano causado por $H$. virescens e $H$. zea, os quais atuam de forma distinta sobre o parasitóide $C$. nigriceps, ou seja, o parasitóide consegue discriminar entre os compostos produzidos por plantas atacadas pelo seu hospedeiro de plantas atacadas pelo inseto não-hospedeiro (DE MORAES et al., 1998). Exemplo semelhante foi verificado com o parasitóide Aphidius ervi Haliday, que consegue distinguir plantas atacadas pelo seu hospedeiro Acyrthosiphon pisum (Harris) de plantas atacadas por Aphis fabae (Scop.) (POWELL et al., 1998). Isso exemplifica a sofisticada interação entre o herbívoro, a planta, e seus compostos e o parasitóide. Além disso, evidências sugerem que os compostos voláteis induzidos pelos herbívoros, além de facilmente detectáveis e de serem indicadores seguros da presença de herbívoros, podem transmitir informação específica que permite aos parasitóides discriminarem, a longas distâncias, espécies de herbívoros muito próximas (DE MORAES et al., 2000).

As interações sinérgicas ocorrem pela exposição dos inimigos naturais à mistura de compostos, uma vez que as plantas produzem grande diversidade de componentes químicos. Os compostos voláteis produzidos em função da alimentação por organismos 
associados ao hospedeiro ou pelo próprio hospedeiro auxiliam na localização do hospedeiro pelo parasitóide, sendo este um dos principais fatores no processo de seleção hospedeira. Uma particularidade interessante é a capacidade dos inimigos naturais de responder às substâncias químicas produzidas pelas plantas atacadas pela praga.

A liberação dos compostos voláteis pelas plantas ocorre não somente em resposta aos danos causados aos seus tecidos, mas é também iniciada pela exposição às secreções salivares dos herbívoros. Alguns compostos voláteis são armazenados nos tecidos vegetais e liberados no momento em que o dano ocorre; outros são induzidos pelo dano causado pelo herbívoro e são, geralmente, liberados, não apenas pelo tecido lesado, mas também pelas folhas não atacadas. Desse modo, o dano causado em algumas folhas resulta na resposta sistêmica e na liberação de compostos voláteis por toda a planta (DE MORAES et al., 2000).

A atratividade aos parasitóides aumenta com a alimentação hospedeira e varia entre as plantas e entre as diferentes partes da planta (LEWIS; SHEEHAN, 1997). Por exemplo, mudanças na arquitetura da planta podem afetar indiretamente o terceiro nível trófico, e diferentes aleloquímicos podem causar efeitos distintos na sobrevivência, no desenvolvimento, na morfologia e no tamanho dos parasitóides.

Os parasitóides e os predadores atuam em contexto multitrófico, ou seja, sua fisiologia e o seu comportamento são influenciados por elementos de outros níveis tróficos, como os herbívoros e as plantas (VET; DICKE, 1992). Dessa forma, o terceiro nível trófico é indispensável para a compreensão da interação da planta com o herbívoro, assim como o papel das plantas é indispensável para a compreensão da relação entre predador e presa. Portanto, é de extrema importância compreender qual é o efeito que as plantas geneticamente modificadas irão exercer sobre o terceiro nível trófico, pois, teoricamente, serão menos danificadas pelos insetos-praga, para que se consiga aumentar a efetividade do controle biológico por meio de predadores e parasitóides.

\section{Considerações finais}

A possibilidade da utilização conjunta do controle biológico e da resistência de plantas por meio das plantas geneticamente modificadas tem assumido importância nas 
últimas décadas, pois, além do potencial de maior eficiência do controle biológico nas variedades resistentes, os inimigos naturais podem retardar o processo de adaptação da praga às plantas transgênicas. No entanto, nem sempre esta associação resulta em interações positivas. A variação deve-se ao fato de que, além dos efeitos provocados por esses dois métodos de controle, existem as interações tritróficas envolvendo a planta, a praga e o inimigo natural.

Outro aspecto a ser considerado é que o uso de plantas transgênicas acarretará a diminuição do uso de inseticidas, principalmente, os de largo espectro, o que favorecerá a manutenção de populações de inimigos naturais e sua atuação no controle de pragas. Portanto, as plantas transgênicas não são substituição aos inseticidas, mas, sim, nova abordagem ao Manejo Integrado de Pragas (MIP), por eliminar ou reduzir drasticamente o uso de inseticidas não seletivos, favorecendo a aliança com o controle biológico, e por reduzir o risco de resistência de insetos aos produtos químicos.

É importante que se defina o que é um impacto ambiental ou um risco ecológico, e qual o ponto de comparação, ou seja, os possíveis impactos das plantas geneticamente modificadas serão comparados com qual método de controle? Portanto, a utilização dessas plantas é uma importante ferramenta e uma tecnologia que poderá romper muitas barreiras e trazer importantes benefícios, no entanto, sua utilização deve ser considerada como mais uma tática dentro do contexto de MIP, e não como uma tática única de controle.

\section{Referências}

AL-DEEB, M. A.; WILDE, G. E.; HIGGINS, R. A. No effect of Bacillus thuringiensis corn and Bacillus thuringiensis on the predator Orius insidiosus (Hemiptera: Anthocoridae). Environmental Entomology, v. 30, n. 3, p. 625-629, 2001.

ARPAIA, S. Ecological impact of Bt-transgenic plants: 1. Assessing possible effects of CryIIIB toxin on honey bee (Apis mellifera L.) colonies. Journal of Genetics \& Breeding, v. 50, p. 315-319, 1996.

ARPAIA, S.; GOULD, F.; KENNEDY, G. Potential impact of Coleomegilla maculata predation on adaptation of Leptinotarsa decemlineata to Bt-transgenic potatoes. Entomologia Experimentalis et Applicata, v. 82, p. 91-100, 1997. 
BELL, H. A. et al. Effect of dietary cowpea trypsin inhibitor (CpTI) on the growth and development of the tomato moth Lacanobia oleracea (Lepidoptera: Noctuidae) and on the success of the gregarious ectoparasitoid Eulophus pennicornis (Hymenoptera: Eulophidae). Pest Management Science, v. 57, p. 57-65, 2001.

BETZ, F. S.; HAMMOND, B. G.; FUCHS, R. L. Safety and advantages of Bacillus thuringiensis-protected plants to control insect pests. Regulatory Toxicology and Pharmacology, v. 32, p. 156-173, 2000.

BHATTI, M. A. et al. Field evaluation of the impact of corn rootworm (Coleoptera: Chrysomelidae)-protected Bt corn on foliage-dwelling arthropods. Environmental Entomology, v. 34, n. 5, p. 1336-1345, 2005.

BLUMBERG, D. et al. Interactions among Helicoverpa armigera (Lepidoptera: Noctuidae), its larval endoparasitoid Microplitis croceipes (Hymenoptera: Braconidae), and Bacillus thuringiensis. Journal of Economic Entomology, v. 90, n. 5, p. 11811186, 1997.

CAROZZI, N.; KOZIEL, M. Advances in insect control. London: Taylor \& Francis, 1997. 301p.

CHILCUTT, C. F.; TABASHNIK, B. E. Simulation of integration of Bacillus thuringiensis and the parasitoid Cotesia plutellae (Hymenoptera: Braconidae) for control of susceptible and resistant diamondback moth (Lepidoptera: Plutellidae). Environmental Entomology, v. 28, n. 3, p. 505-512, 1999.

DE MORAES, C. M. et al. Herbivore-infested plants selectively attract parasitoids. Nature, v. 393, p. 570-573, 1998.

DE MORAES, C. M.; LEWIS, W. J.; TUMLINSON, J. H. Examining plant-parasitoid interactions in tritrophic systems. Anais da Sociedade Entomológica do Brasil, v. 29, n. 2, p. 189-203, 2000.

DEMARCHI, C. R. Comportamento de espécies integrantes do terceiro nível trófico em variedades transgênicas-Bt (Bacillus thuringiensis) de cana-de-açúcar (Saccharum sp.). 2002. 54 p. Dissertação (Mestrado) - Escola Superior de Agricultura "Luiz de Queiroz", Universidade de São Paulo. 2002

DIVELY, G. P. Impact of transgenic VIP3A x Cry1Ab lepidopteran-resistant field corn on the nontarget arthropod community. Environmental Entomology, v. 34, n. 5, p. 1267-1291, 2005.

DOGAN, E. B. et al. Biological parameters of convergent lady beetle (Coleoptera: Coccinellidae) feeding on aphids (Homoptera: Aphididae) on transgenic potato. Journal of Economic Entomology, v. 89, n. 5, p. 1105-1108, 1996. 
DOWD, P. F. Indirect reduction of ear molds and associated mycotoxins in Bacillus thuringiensis corn under controlled and open field conditions: utility and limitations. Journal of Economic Entomology, v. 93, n. 6, p. 1669-1679, 2000.

FERRY, N. et al. Prey-mediated effects of transgenic canola on a beneficial, non-target, carabid beetle. Transgenic Research, v. 15, n. 4, p. 501-514, 2006.

FONTES, E. M. G.; MELO, P. E. Avaliação de riscos na introdução no ambiente de plantas transgênicas. In: TORRES, A. C.; CALDAS, L. S.; BUSO, J. A. (Eds.). Cultura de tecidos e transformação genética de plantas. Brasília: Embrapa-SPI/EmbrapaCNPH, 1999. v. 2, p. 815-843.

GILL, S. S. Mechanism of action of Bacillus thuringiensis toxins. Memórias do Instituto Oswaldo Cruz, v. 90, n. 1, p. 69-74, 1995.

GLARE, T. R.; O'CALLAGHAN, M. Bacillus thuringiensis: biology, ecology and safety. Chichester: John Wiley, 2000. 350p.

GOULD, F. Sustainability of transgenic insecticidal cultivars: integrating pest genetics and ecology. Annual Review of Entomology, v. 43, p. 701-726, 1998.

GOULD, F.; KENNEDY, G. G.; JOHNSON, M. T. Effects of natural enemies on the rate of herbivore adaptation to resistant host plants. Entomologia Experimentalis et Applicata, v. 58, p. 1-14, 1991.

HELLMICH, R. L. et al. Monarch larvae sensitivity to Bacillus thuringiensis-purified proteins and pollen. Proceedings of the National Academic of Science of the United States of America, v. 98, n. 21, p. 11925-11930, 2001.

HILBECK, A. et al. Effects of transgenic Bacillus thuringiensis corn-fed prey on mortality and development time of immature Chrysoperla carnea (Neuroptera: Chrysopidae). Environmental Entomology, v. 27, n. 2, p. 480-487, 1998a.

HILBECK, A. et al. Toxicity of Bacillus thuringiensis Cry 1Ab toxin to the predator Chrysoperla carnea (Neuroptera: Chrysopidae). Environmental Entomology, v. 27, n. 5, p. 1255-1263, 1998b.

HOFS, J. L. et al. Impact of genetically modified cotton on the biodiversity of the insect fauna: the case of Bt cotton in South Africa. International Journal of Tropical Insect Science, v. 25, n. 2, p. 63-72, 2005.

HOY, C. W. et al. Naturally occurring biological controls in genetically engineered crops. In: BARBOSA, P. (Ed.). Conservation biological control. San Diego: Academic Press, 1998. cap. 10, p. 185-205.

JAMES, C. Global review of commercialized transgenic crops: 2006. ISAAA (Briefs, 36: Preview). Ithaca: ISAAA, 2006. 20p. 
JIANG, Y. H. et al. Effect of transgenic sck+cry1Ac rice on the survival and growth of Chilo suppressalis (Walker) (Lepidoptera: Pyralidae) and its parasitoid Apanteles chilonis (Munakata) (Hymenoptera: Braconidae). Acta Entomologica Sinica, v. 48, n. 4, p. 554-560, 2005.

JOHNSON, K. S. et al. Toxicity of Bacillus thuringiensis var. kurstaki to three nontarget Lepidoptera infield studies. Environmental Entomology, v. 24, n. 2, p. 288297, 1995.

JOHNSON, M. T. Interaction of resistant plants and wasp parasitoids of tobacco budworm (Lepidoptera: Noctuidae). Environmental Entomology, v. 26, n. 2, p. 207214, 1997.

JOHNSON, M. T. et al. Effects of natural enemies on relative fitness of Heliothis virescens genotypes adapted and not adapted to resistant host plants. Entomologia Experimentalis et Applicata, v. 82, p. 219-230, 1997.

JOHNSON, M. T; GOULD, F. Interaction of genetically engineered host plant resistance and natural enemies of Heliothis virescens (Lepidoptera: Noctuidae) in tobacco. Environmental Entomology, v. 21, n. 3, p. 586-597, 1992.

LEWIS, W. J.; SHEEHAN, W. Parasitoid foraging from a multitrophic perspective: significance for biological control. In: ANDOW, D.A.; RAGSDALE, D.W.; NYVALL, R.F. (Ed.). Ecological interactions and biological control. Boulden: Westview Press, 1997. cap. 17, p. 271-281.

LÓPEZ, R.; FERRO, D. N. Larviposition response of Myiopharus doryphorae (Diptera: Tachinidae) to colorado potato beetle (Coleoptera: Chrysomelidae) larvae treated with lethal and sublethal doses of Bacillus thuringiensis Berliner subsp. tenebrionis. Journal of Economic Entomology, v. 88, n. 4, p. 870-874, 1995.

LOSEY, J. E.; RAYOR, L. S.; CARTER, M. E. Transgenic pollen harms monarch larvae. Nature, v. 399, p. 214, 1999.

LOZZIA, G. C. et al. Effects of Bt corn on Rhopalosiphum padi L. (Rhynchota: Aphididae) and on its predator Chrysoperla carnea Stephen (Neuroptera: Chrysopidae). Bollettino di Zoologia agraria e di Bachicoltura, v. 30, n. 2, p. 153-164, 1998.

MALONE, L. A. et al. Toxicity of trypsin endopeptidase inhibitors to honey bees (Hymenoptera: Apidae). Journal of Economic Entomology, v. 88, n. 1, p. 46-50, 1995.

MASCARENHAS, V. J.; LUTTRELL, R. G. Combined effect of sublethal exposure to cotton expressing the endotoxin protein of Bacillus thuringiensis and natural enemies on survival of bollworm (Lepidoptera: Noctuidae) larvae. Environmental Entomology, v. 26, n. 4, p. 939-945, 1997. 
MONNERAT, R.; BRAVO, A. Proteínas bioinseticidas produzidas pela bactéria Bacillus thuringiensis: modo de ação e resistência. In: MELO, I. S.; AZEVEDO, J. L. (Eds.). Controle biológico. Jaguariúna: EMBRAPA Meio Ambiente, 2000. p. 163-200.

NARANJO, S. E. Long-term assessment of the effects of transgenic Bt cotton on the abundance of nontarget arthropod natural enemies. Environmental Entomology, v. 34, n. 5, p. 1193-1210, 2005.

OBERHAUSER, K. S. et al. Temporal and spatial overlap between monarch larvae and corn pollen. Proceedings of the National Academic of Science of the United States of America, v. 98, n. 21, p. 11913-11918, 2001.

ORR, D. B.; LANDIS, D. A. Oviposition of european corn borer (Lepidoptera: Pyralidae) and impact of natural enemy populations in transgenic versus isogenic corn. Journal of Economic Entomology, v. 90, n. 4, p. 905-909, 1997.

PICARD-NIZOU, A. L. et al. Impact of proteins used in plant genetic engineering: toxicity and behavioral study in the honeybee. Journal of Economic Entomology, v. 90, n. 6, p. 1710-1716, 1997.

PILCHER, C. D; RICE, M. E.; OBRYCKI, J. J. Impact of transgenic Bacillus thuringiensis corn and crop phenology on five nontarget arthropods. EnvironmentalEntomology, v. 34, n. 5, 1302-1316, 2005.

PILCHER, C. D. et al. Preimaginal development, survival, and field abundance of insect predators on transgenic Bacillus thuringiensis corn. Environmental Entomology, v. 26, n. 2, p. 446-454, 1997.

PIMENTEL, D. S.; RAVEN, P. H. Bt corn pollen impacts on nontarget Lepidoptera: assessment of effects in nature. Proceedings of the National Academic of Science of the United States of America, v. 97, n. 15, p. 8198-8199, 2000.

PLEASANTS, J. M. et al. Corn pollen deposition on milkweeds in and near cornfields. Proceedings of the National Academic of Science of the United States of America, v. 98, n. 21, p. 11919-11924, 2001.

POWELL, W. et al. Strategies involved in the location of hosts by the parasitoid Aphidius ervi Haliday (Hymenoptera: Braconidae: Aphidiinae). Biological Control, v. 11, p. 104-112, 1998.

POZA, M. et al. Impact of farm-scale Bt maize on abundance of predatory arthropods in Spain. Crop Protection, v. 24, n. 7, p. 677-684, 2005.

RAPS, A. et al. Immunological analysis of phloem sap of Bacillus thuringiensis corn and of the nontarget herbivore Rhopalosiphum padi (Homoptera: Aphididae) for the presence of Cry1Ab. Molecular Ecology, v. 10, p. 525-533, 2001. 
RIDDICK, E. W.; BARBOSA, P. Impact of Cry3A-intoxicated Leptinotarsa decemlineata (Coleoptera: Chrysomelidae) and pollen on consumption, development, and fecundity of Coleomegilla maculata (Coleoptera: Coccinellidae). Annals of the Entomological Society of America, v. 91, n. 3, p. 303-307, 1998.

RIDDICK, E. W.; DIVELY, G.; BARBOSA, P. Effect of a seed-mix deployment of Cry3A-transgenic and nontransgenic potato on the abundance of Lebia grandis (Coleoptera: Carabidae) and Coleomegilla maculata (Coleoptera: Coccinellidae). Annals of the Entomological Society of America, v. 91, n. 5, p. 647-653, 1998.

RIGGIN-BUCCI, T. M.; GOULD, F. Impact of intraplot mixtures of toxic and nontoxic plants on population dynamics of diamondback moth (Lepidoptera: Plutellidae) and its natural enemies. Journal of Economic Entomology, v. 90, n. 2, p. 241-251, 1997.

ROMEIS, J; MEISSLE, M.; BIGLER, F. Transgenic crops expressing Bacillus thuringiensis toxins and biological control. Nature Biotechnology, v. 24, n. 1, p. 6371, 2006.

SCHULER, T.H. The impact of insect resistant GM crops on populations of natural enemies. Antenna-London, v. 24, n. 2, p.59-65, 2000.

SCHULER, T.H. et al. Potential side effects of insect-resistant transgenic plants on arthropod natural enemies. Trends in Biotechnology, v. 17, p. 210-216, 1999.

SCHULER, T.H. et al. Parasitoid behaviour and Bt plants. Nature, v. 400, p. 835-836, 2000 .

SCHULER, T. H. et al. Effects of Bt plants on the development and survival of the parasitoid Cotesia plutellae (Hymenoptera: Braconidae) in susceptible and Bt-resistant larvae of the diamondback moth, Plutella xylostella (Lepidoptera: Plutellidae). Journal of Insect Physiology, v. 50 n. 5, p. 435-443, 2004.

SIMS, S. R. Bacillus thuringiensis var. kurstaki [CryIA(c)] protein expressed in transgenic cotton: effects on beneficial and other non-target insects. Southwestern Entomologist, v. 20, n. 4, p. 493-500, 1995.

STANLEY-HORN, D. E. et al. Assessing the impact of Cry1Ab-expressing corn pollen on monarch butterfly larvae in field studies. Proceedings of the National Academic of Science of the United States of America, v. 98, n. 21, p. 11931-11936, 2001.

VANDENBERG, J. D. Safety of four entomopathogens for caged adult honey bees (Hymenoptera: Apidae). Journal of Economic Entomology, v. 83, n. 3, p. 755-759, 1990.

VET, L. E. M.; DICKE, M. Ecology of infochemical use by natural enemies in a tritrophic context. Annual Review of Entomology, v. 37, p. 141-172, 1992. 
WANG, C. L.; LIN, F. C.; LIN, C. Y. Insect-resistant transgenic plants and the environmental impact assessment - special concern for insects. Plant Protection Bulletin, v. 46, n. 3, p. 181-209, 2004.

WRAIGHT, C.L. et al. Absence of toxicity of Bacillus thuringiensis pollen to black swallowtails under field conditions. Proceedings of the National Academic of Science of the United States of America, v. 97, n. 14, p. 7700-7703, 2000.

ZHANG, Y. J. et al. Effects of transgenic Bt-cry1Ab corn pollen on the growth and development and the activity of three metabolic enzymes in Harmonia axyridis (Pallas) (Coleoptera: Coccinellidae). Acta Entomologica Sinica, v. 48 n. 6, p. 898-902, 2005.

ZWAHLEN, C. et al. Tritrophic interactions of transgenic Bacillus thuringiensis corn, Anaphothrips obscurus (Thysanoptera: Thripidae), and the predator Orius majusculus (Heteroptera: Anthocoridae). Environmental Entomology, v. 29, n. 4, p. 846-850, 2000. 